\title{
Gênero e pobreza multidimensional no município de Porto Alegre, Rio Grande do Sul *
}

\author{
Izete Pengo Bagolin ** \\ Osmar Tomaz de Souza ${ }^{* * *}$ \\ Flavio V. Comim ${ }^{* * * *}$
}

\begin{abstract}
Resumo
Este trabalho buscou identificar e dar visibilidade às múltiplas dimensões da pobreza, incluindo aí seus aspectos espaciais e as particularidades das desigualdades de gênero em Porto Alegre. Ele está baseado em resultados de pesquisa, na qual foram entrevistadas 16.386 pessoas vivendo em situação de pobreza nas diferentes regiões da cidade. A pesquisa buscou uma mudança de foco na análise sobre pobreza ao enfatizar o peso das dimensões que as pessoas consideram relevante para uma vida "digna de ser vivida". Os resultados evidenciaram a importância de dimensões como habitação, saúde e educação para viabilizar às pessoas uma vida "digna de ser vivida". Igualmente, mostraram as diferenças nas privações entre homens e mulheres, a heterogeneidade entre as regiões de Porto Alegre e, em especial, as formas como homens e mulheres vivenciam e manifestam suas percepções acerca da pobreza e das privações.
\end{abstract}

Palavras-chave: Pobreza; Gênero; Desigualdade; Capacitações.

\begin{abstract}
Multidimensionality in gender and poverty in Porto Alegre, Rio Grande do Sul

This paper aims to discuss the importance of multidimensionality in understanding poverty in Porto Alegre, as well as to identify the spatial and gender disparities among its regions. The paper was based on a dataset from a survey conducted in 2007, in a two-stage methodology in which 16386 people living in poverty were interviewed. The results enabled the researchers to highlight the importance of dimensions such as habitation, health and education to allow people to "live a "dignified life". It also shows the differences in deprivations between men and women, the heterogeneity among the Porto Alegre regions and, in particular, the way in which men and women shape their perceptions of poverty and deprivation.
\end{abstract}

Keywords: Poverty; Gender; Inequality; Capability.

JEL I3, I32, O15.

\section{Introdução}

Pobreza, desigualdade de oportunidades, baixo desenvolvimento e exclusão social no Brasil e na América Latina são temas de pesquisas e reflexões de longa data no campo da Economia e das Ciências Sociais. Desde o início deste século,

\footnotetext{
* Trabalho recebido em 6 de março de 2009 e aprovado em 9 de junho de 2011.

** Professora do Programa de Pós-Graduação em Economia do Desenvolvimento da Pontifícia Universidade Católica do Rio Grande do Sul (PPGE/PUCRS), Porto Alegre, RS, Brasil. E-mail: izete.bagolin@pucrs.br.

${ }^{* * * *}$ Professor do PPGE/PUCRS, Porto Alegre, RS, Brasil. E-mail: osmar.souza@pucrs.br.

**** Professor do PPGE/UFRGS e da Universidade de Cambridge, Inglaterra. E-mail: fvc1001@cam.ac.uk.
} 
entretanto, intensificaram-se os debates acerca de tal complexidade, em especial, sobre sua articulação com diversos outros aspectos da realidade econômica e social contemporânea. Isso porque o estudo e a compreensão dos citados fenômenos sem articulá-los com particularidades regionais, locais, setoriais, de grupos sociais, de gênero etc. limitam muito as possibilidades enquanto inspiradores para as ações de combate à pobreza e promoção do desenvolvimento.

A aceitação da complexidade do tema vem renovando a agenda de pesquisas sobre pobreza e permitindo o desenvolvimento e a incorporação de novas abordagens em seu estudo e mensuração. Exemplificam-se por meio da análise sobre pobreza orientada pela abordagem das capacitações, cujas bases teóricas e conceituais foram inicialmente estabelecidas por Sen (1982, 2000), por Nussbaum (1999, 2000) e vem sendo aperfeiçoadas por autores como Comin (2001), Comim e Bagolin (2002), Chiapero Martinetti (2000), Qizilbash (2002) dentre outros. Trata-se de uma mudança de perspectiva na visão de pobreza, na formação de bases informacionais e, claro, na forma de pensar intervenções no sentido de combatê-la.

Assim, é necessário destacar que a verdadeira "essência" de uma abordagem depende não apenas do que ela considera importante para avaliação, mas também o que ignora. O principal aporte teórico da Abordagem da Capacitação (AC) como um framework normativo amplo é justamente expandir o espaço informacional ao nível dos funcionamentos e das capacitações, ou seja, da liberdade substantiva (capacitação) de uma pessoa para escolher uma vida que ela tem razão para valorizar por meio dos estados e ações (funcionamentos realizados).

AAC contrasta, dessa forma, com as abordagens filosóficas que se concentram nos estados mentais, como felicidade ou satisfação de desejos, nos bens primários e com as teorias baseadas em renda, gasto, consumo ou necessidades básicas. Ao enfatizar que - "em certo sentido", o enfoque das capacitações ou liberdades substantivas e da qualidade de vida é "um afastamento das tradições estabelecidas na economia" - Sen (2000, p. 39) coloca que "essas abordagens mais amplas estão em sintonia com as linhas de análise que têm sido parte da economia profissional desde o princípio".

Como esclarece Sen $(1992 ; 1993 ; 2000)$, a base filosófica da AC pode ser identificada no enfoque sobre "florescimento humano" e "capacitação", relacionados à qualidade de vida e às liberdades substantivas que derivam de elementos presentes nas ideias de Aristóteles. Já, as conexões com Adam Smith, conforme Sen (1984; $1984 b ; 1985 ; 1987 ; 1992 ; 1993 ; 1999,2000)$, centram-se na análise sobre as "necessidades" e as "condições de vida". Smith (1976) considerava a necessidade de satisfação de algumas liberdades, como por exemplo, "a capacidade de aparecer em público sem se envergonhar" ou de participar da vida da comunidade. Sen (1984b; 1987; 1992; 1993; 2000) destaca que na filosofia política de Marx pode 
ser encontrada a defesa do valor básico da liberdade, com ênfase em incluir "sob o controle dos indivíduos as condições para suas atividades e livre desenvolvimento". Sen $(1984 ; 1985 ; 1987)$ aponta também outra contribuição importante relacionada ao que Marx chamou de "fetiche da mercadoria" - considerar bens como valiosos por eles mesmos e não pelo que eles ajudam as pessoas. Já, Mill apud Sen (1984b; 2000), teve sua perspectiva utilitarista suplantada ao julgar interesses em termos da extensão da liberdade.

Indicadas algumas das fontes teóricas da AC, deve-se enfatizar que a perspectiva é fundamentada principalmente em Sen $(1980 ; 1984 ; 1984 b ; 1985$; 1987 ; 1992; 1993; 2000) e, de forma complementar, em Nussbaum (2000).

A AC pode ser distinguida em três níveis diferentes, de acordo com Pressman e Summerfield (2000, p.90) e Robeyns (2003; 2005):

1. Como um framework de pensamento para avaliação de vantagens individuais ou arranjos sociais;

2. Como uma crítica a outras abordagens para avaliação de bem-estar e justiça;

3. Como uma contribuição para operacionalizar comparações interpessoais de bem-estar e mensurar pobreza e desigualdade.

Na Abordagem da Capacitação, de acordo com Sen (1983b; 1984; 1992; 1993; 2000), a pobreza deve ser compreendida como privação de capacitações básicas e não apenas como insuficiência de renda ou baixo nível de recursos, bens primários ou necessidades básicas.

O autor (1992, p.109-110; 1993, p. 41) explica que a utilização do termo “capacitações básicas" (em Sen, 1980; 1983b) visava a separar a capacitação para satisfazer determinados funcionamentos muito importantes de certos níveis minimamente adequados. Como já apontado, essa condição mínima pode ser representada pelos funcionamentos mais elementares como estar bem nutrido, saudável, livre de doenças que podem ser evitadas e da morte prematura, até maior complexidade como ser feliz, ter respeito próprio e participar da vida comunitária.

A partir disso, salienta Sen $(1992 ; 1993)$ que a identificação de níveis minimamente aceitáveis de determinadas capacitações básicas pode fornecer uma abordagem possível para pobreza. Segundo ele (1993, p. 41), “identificar uma combinação mínima de capacitações básicas pode ser um bom caminho para determinar o problema de diagnosticar e mensurar pobreza".

Sen (2000) adverte, contudo, que o objetivo da AC não é negar que o baixo nível de renda é uma das causas principais da pobreza. Sen (1992, p. 111) explica que "ter uma renda inadequada não é uma questão de ter um nível de renda abaixo de uma linha de pobreza fixada externamente, mas de ter uma renda abaixo do que 
é adequado para gerar os níveis especificados de capacitações para a pessoa em questão". Assim, de acordo com Sen (1992, p.111) e Foster e Sen (1997, p.213), no espaço de rendas, "o conceito relevante de pobreza tem de ser a inadequação (para gerar as capacitações minimamente aceitáveis), em vez de um nível baixo (independente das características pessoais)".

Sen (2000, p.110) e Foster e Sen (1997, p. 211) sugerem alguns argumentos em favor da abordagem da pobreza como privação de capacitações:

1. Pobreza pode ser identificada com sensatez em termos de privação de capacitações muito importantes em contraste com a renda, necessária apenas instrumentalmente;

2. Há influências na privação de capacitações mais do que na insuficiência de renda;

3. O impacto da baixa renda sobre as capacitações é contingente e condicional, ou seja, a relação instrumental entre insuficiência de renda e baixa capacitação é variável entre comunidades e até mesmo entre famílias e indivíduos.

Desses argumentos, Sen ressalta que o terceiro é particularmente importante para propósitos de análise da ação pública com o objetivo de redução da pobreza ou da desigualdade. Sen (2000, p. 110 e 111) e Foster e Sen (1997, p. 211-213) enumeram algumas razões sobre as "variações condicionais" discutidas pela literatura no contexto da elaboração de políticas públicas:

1. A conexão entre renda e capacitação é fortemente influenciada pela diversidade humana, tanto nas características pessoais como em suas circunstâncias externas. Ademais, as pessoas podem não ter o controle ou possuí-lo apenas de forma limitada sobre algumas das variáveis relacionadas a tal diversidade;

2. Pode existir um determinado "acoplamento" de desvantagens entre (1) privação de renda e (2) adversidade na conversão de renda em funcionamentos. Desvantagens como idade, incapacidade ou doença não só diminuem o potencial do indivíduo para auferir renda, como também tornam mais difícil converter renda em capacitação;

3. Levar em conta apenas a renda familiar é ignorar a desigualdade dentro da família e o grau de privação dos membros negligenciados;

4. A privação relativa de rendas pode resultar em privação absoluta de capacitações.

A partir disso, Sen (1992, p. 116) enfatiza que considerar apenas a insuficiência de renda, além de "ficar bem longe da principal motivação por trás de nosso interesse pela pobreza (que é a limitação das vidas que algumas pessoas são 
forçadas a viver)", pode "deixar de apresentar orientação empírica quanto à gênese e predomínio de privação". De acordo com Sen (2000, p. 112), analisar a pobreza como privação de capacitações "é melhorar o entendimento da sua natureza e das suas causas desviando a atenção principal dos meios para os fins que as pessoas têm razão para buscar e, correspondentemente, para as liberdades de poder alcançar esses fins". É no contexto de tais reflexões que o artigo apresenta contribuições.

O foco da análise centra-se, sobretudo, na compreensão das diferenças na forma como homens e mulheres veem e expressam sua visão da pobreza. No texto, mais do que o debate teórico das questões de gênero, enfatiza-se a perspectiva dos homens e mulheres respondentes o que, entende-se, ilustra a forma como essa experiência é percebida e vivida pelos diferentes sexos. Busca-se com este trabalho atender a dois objetivos distintos: i) reconhecer e dar visibilidade às múltiplas dimensões da pobreza, incluindo aí seus aspectos espaciais e as particularidades das desigualdades sexuais em Porto Alegre; ii) contribuir no sentido de revelar a realidade das desigualdades e constituir informação fundamental, visando a legitimar questões de fundo sobre o tema, sensibilizar a sociedade e, sobretudo, auxiliar na construção de políticas públicas.

\section{Pobreza, provações e gênero}

Em geral, o olhar sobre a pobreza vem-se assentando principalmente sobre as privações de renda. Instituições e organismos internacionais, como o próprio Programa das Nações Unidas para o Desenvolvimento (PNUD), utilizam-se do critério "renda" como recorte para a definição de "pobres" e de pessoas em situação de "pobreza extrema". Apesar da facilidade de utilização desse critério, entretanto, é de razoável consenso que ele não consiga captar o sentido e a profundidade daquilo que significa ser "pobre". A criação e ampla utilização do Índice de Desenvolvimento Humano (IDH) foi um avanço no sentido de relativizar o uso da Renda per Capita como indicador de desenvolvimento.

Sen (2000), um dos inspiradores do IDH, aponta a importância da mudança no olhar sobre a pobreza, pois ainda que privações de renda e privações de capacitações em geral apresentem "consideráveis encadeamentos correlatos, é importante não cairmos na ilusão de pensar que levar em conta as primeiras de algum modo nos dirá alguma coisa sobre as segundas" (p. 34). Assim, as correlações nem sempre são tão fortes e, às vezes, os afastamentos é que são mais importantes. Sen ressalta ainda que a pobreza vista como privação das capacitações básicas pode refletir-se em diferentes aspectos, como por exemplo, em morte prematura, analfabetismo, subnutrição e mesmo no fenômeno da desigualdade entre os sexos.

A questão da desigualdade entre os sexos e o debate sobre a construção histórica e teórica da categoria "gênero" vem-se tornando profícuo no campo 
acadêmico e político brasileiro. É uma tentativa de dar voz e visibilidade ao papel das mulheres e a importância que elas têm, sobretudo, nos processos históricos. Seja tratando o tema nos aspectos constitutivos e históricos para Gonçalves (2006); Strey et. al. (2004) ou ligados ao mundo do trabalho, família e políticas públicas conforme Carreira (2004); Olinto e Oliveira, (2004); Araújo e Scalon (2005); Scott e Cordeiro (2006), verifica-se a ampliação do leque de pesquisas e publicações que buscam romper com a aparente "neutralidade" de dados quantitativos e das narrativas históricas.

Conforme já se apontou previamente, não é objetivo aqui, assim como não o foi na pesquisa de campo, o aprofundamento das reflexões teóricas ligadas a essa categoria "Gênero". Por acreditar, contudo, na contribuição que tal recorte pode dar à compreensão da pobreza e às políticas públicas que busquem sua superação é que se empreendeu o esforço de analisar os dados a partir das desigualdades de visões e perspectivas entre os sexos.

Quanto à articulação dos dois temas, o Observatório da Cidadania é ilustrativo ao apontar que "a pobreza afeta homens, mulheres, meninos e meninas, porém essa experiência é vivida de forma diferente por pessoas de idades, etnias, papéis [sic] familiares e sexos distintos" (2005, p. 27). Tanto quanto o fenômeno da pobreza no sentido mais geral, a desigualdade de gênero também extrapola as abordagens metodológicas em uso, conforme ressalta o mesmo documento ao fazer referência aos “... problemas metodológicos de medição da pobreza que escondem as questões de gênero" (p. 27). Ainda o Social Watch, em seu relatório de 2007 reconhece que:

Gender-based inequity is a phenomenon that transcends borders, cultures, religions, nations and income levels. The achievement of gender equity is a challange for the entire modern world because although its manifestations are diverse, the gap between women and men persists in all countries (2007, p. 85).

O relatório do Observatório da Cidadania (2005) vai mais longe ao enfatizar que pobreza e gênero "estão inextricavelmente vinculados" e que, a despeito dessa realidade, o gênero “... na prática, recebe pouca atenção nos planos de ação e nos projetos de desenvolvimento específicos” (p. 27).

A Abordagem das capacitações pode ser considerada uma das alternativas mais abrangentes no atual debate relacionado ao desenvolvimento. Tal abordagem tem sido usada com diferentes propósitos em estudos multidisciplinares nas mais diversas áreas do conhecimento. Mesmo assim, as aplicações práticas e/ou empíricas ainda são limitadas e passíveis de críticas e discussões. Não existe consenso a respeito de como operacionalizar a abordagem ou de como avaliar políticas públicas implementadas a partir dos princípios da abordagem. Assim, sua operacionalização e a aplicação ainda podem ser consideradas como aspectos restritos, que demandam esforços adicionais de pesquisa. 
A partir das citadas distinções e no contexto deste trabalho, dizer que a proporção de pobres, medida como insuficiência de renda, em Porto Alegre, praticamente não sofreu alteração na década de 1990, passando de $11 \%$ da população, em 1991, para 11,3\%, em 2000, é uma conclusão bastante limitada. Tal informação esconde as outras faces da pobreza na capital gaúcha. Questões básicas como estar nutrido adequadamente, estar bem de saúde, livre de doenças que podem ser evitadas e morte prematura, até coisas mais complexas, como ser feliz, ter respeito próprio e participar da vida comunitária são ignoradas por esse indicador de pobreza.

\section{Aspectos metodológicos da pesquisa}

É comum que se encontrem, quando da realização de surveys e questionários, perguntas formuladas por pesquisadores e institutos sem nenhuma participação ou input dos entrevistados. As pessoas entrevistadas, que deveriam beneficiar-se das pesquisas, acabam servindo muitas vezes apenas como instrumento, como um meio para a legitimação de teses dos pesquisadores já incorporadas em questões formuladas em gabinetes. Pesquisadores que, conscientes desse problema, tentam evitá-lo, podem cair na armadilha de condução de grupos focais, com pautas muitas vezes abertas, limitando-se ao relato descritivo de conversas sem um fio condutor coerentemente atrelado ao objeto da pesquisa. Inúmeras vezes, consultas ao público são utilizadas como maneira de justificar ou legitimar resultados, quando feitas sem o devido cuidado, deixando as pessoas pobres influírem na definição das dimensões a serem contempladas pelos estudos.

Buscando superar essas dificuldades, a pesquisa sobre Pobreza Multidimensional em Porto Alegre foi dividida em duas etapas distintas, porém complementares. A primeira etapa foi denominada de Consulta Popular e constituiuse em um estágio preliminar na formulação das questões utilizadas no questionário construído e aplicado na segunda etapa a qual pode ser chamada de Coleta de Dados.

A consulta popular foi realizada por meio da implementação de questionários individuais de uma página. A partir dos resultados, foi elaborado o questionário para a coleta dos dados e construção do indicador multidimensional de pobreza.

Observe-se que o foco da pesquisa não foi separar pobres de não pobres, mas mensurar a intensidade da pobreza multidimensional. Em função disso, a distribuição amostral dentro de cada região seguiu a lógica de entrevistar pessoas morando em lugares sabidamente pobres. Tais focos de pobreza foram previamente identificados pelos moradores das respectivas regiões do orçamento participativo, em um processo de mapeamento dos focos de pobreza. Assim, identificaram-se 202 focos de pobreza (vilas, becos, favelas etc.) muitos dos quais sequer constavam dos registros da prefeitura. 
Em seu sentido mais amplo, a pesquisa teve dois objetivos principais. $\mathrm{O}$ primeiro foi fazer um levantamento sobre a visão que as pessoas pobres têm de sua pobreza. A metodologia utilizada assemelha-se em escopo e propósito a estudos do tipo 'Vozes dos Pobres', coordenado por Narayan (2000) em nome do Banco Mundial. Aqui, foram feitas questões de caráter amplo e interativamente refinadas com base nos dados emergentes da própria pesquisa. O objetivo foi obter uma informação qualitativa rica e densa sobre a natureza da pobreza vivida pelas pessoas em Porto Alegre. Em estudos desse tipo, são usadas técnicas amostrais que variam muito, como discutido por Narayan et. al. (2000, p. 17-18),

Sampling techniques ranged from nationally representative samples to purposive sampling based primarily on poverty, agro-ecological diversity, and rural and urban diversity. Sample sizes varied from less than one hundred to 5,000 people. Some studies focused only on the poor while others included the non-poor.

No caso do estudo em evidência, o foco centra-se apenas nas pessoas já sabidamente pobres.

O segundo objetivo foi construir um indicador de pobreza multidimensional para Porto Alegre. No caso, o ponto importante para a definição do Plano Amostral era não existir a possibilidade de se eleger algo 'representativo' antes de fazer a pesquisa. Motivo pelo qual a pesquisa, em seu primeiro estágio, possuiu um caráter consultivo, ou seja, serviu como um instrumento de voz dos mais pobres da cidade quanto aos problemas vividos por eles.

Considerando uma taxa de pobreza monetária da ordem de $11 \%$ para Porto Alegre, está-se falando de um universo de mais de 150.000 pessoas pobres. Baseado no Piloto feito na pesquisa, estimava-se que o número de pobres multidimensionais seria superior a isso. Assim, para fundamentar a escolha do tamanho amostral, buscaram-se as melhores práticas em estudos similares e algumas considerações teóricas.

A referência internacional na construção de surveys domiciliares, Angus Deaton comenta em seu livro The Analysis of Household Surveys (1998, p. 10) que tamanhos amostrais de 10.000 são os mais frequentemente encontrados em estudos assim. É obvio, salienta o autor, que o Plano Amostral depende do propósito do survey, do tamanho da população e do grau de subdivisão dos subgrupos.

É importante enfatizar que a pesquisa conduzida não se encaixa em um Plano Amostral convencional como é feito, por exemplo, em pesquisas eleitorais. Nesse caso, não se conhecia a população a ser investigada e conduzia-se um processo investigativo e, ao mesmo tempo, consultivo. Estruturou-se, então, um processo de construção de razão pública, em que simplesmente quanto maior o número de participações, melhor. As restrições foram mais de ordem orçamentária e logística. Qualquer justificativa de tamanho amostral em tal caso não pode resultar da simples 
aplicação de uma fórmula, pois existem vários parâmetros ainda desconhecidos. Isso não invalida o processo proposto, pois, ao adotar o referencial amostral superior em referentes estudos, garantem-se os níveis de precisão amostrais mínimos que são exigidos para confiabilidade nos resultados. Na pesquisa realizada, somadas as duas etapas, foram obtidos 16.386 questionários válidos. A distribuição das entrevistas entre as 16 regiões do orçamento participativo de Porto Alegre encontra-se no Quadro 1.

Quadro 1

Distribuição da amostra - questionários válidos - entre as Regiões do Orçamento Participativo de Porto Alegre - Consulta e Questionário II

\begin{tabular}{|l|c|c|}
\hline Regiões OP & Questionário I - Consulta & $\begin{array}{c}\text { Questionário II - Coleta } \\
\text { de dados }\end{array}$ \\
\hline Região 01 - Humaitá/Navegantes/Ilhas & 587 & 725 \\
\hline Região 02 - Noroeste & 531 & 604 \\
\hline Região 03 - Leste & 256 & 567 \\
\hline Região 04 - Lomba do Pinheiro & 289 & 275 \\
\hline Região 05 - Norte & 653 & 1.169 \\
\hline Região 06 - Nordeste & 535 & 341 \\
\hline Região 07 - Partenon & 801 & 1.048 \\
\hline Região 08 - Restinga & 573 & 501 \\
\hline Região 09 - Glória & 595 & 766 \\
\hline Região 10 - Cruzeiro & 360 & 739 \\
\hline Região 11 - Cristal & 215 & 116 \\
\hline Região 12 - Centro-Sul & 511 & 329 \\
\hline Região 13 - Extremo-Sul & 537 & 608 \\
\hline Região 14 - Eixo-Baltazar & 258 & 193 \\
\hline Região 15 - Sul & 40 & 890 \\
\hline Região 16 - Centro & 642 & 9.003 \\
\hline Total & 7.383 & 132 \\
\hline
\end{tabular}

Fonte: Elaborada pelos autores; resultado da pesquisa.

$\mathrm{Na}$ primeira etapa, foram entrevistadas 7383 pessoas residentes nas 16 regiões do orçamento participativo da cidade. Na segunda, 10.220 pessoas. Após a eliminação dos questionários incompletos, suspeitos ou com problemas de preenchimento, restaram 9003 questionários válidos para construção do indicador.

\section{Resultados da pesquisa}

Os resultados da pesquisa contribuem para o entendimento das características e distribuição espacial das privações nas diferentes regiões e nos diferentes grupos 
sociais. Para tanto, foi construído um índice multidimensional de carências (IC). Tal índice não serve para discriminar quem é pobre e quem não é, uma vez que a população entrevistada, objeto da pesquisa, é composta, exclusivamente, de pessoas que vivem em situação de pobreza. Em contrapartida, os resultados são úteis para entender-se em quais das dimensões a pobreza é mais intensa, pois o IC é um índice composto de quatro dimensões (Habitação, Saúde, Educação e Trabalho e Renda). Essas dimensões foram definidas após a primeira etapa da pesquisa e, conforme já mencionado, "eleitas" pelas pessoas que vivem em situação de pobreza. Embora se tratando de dimensões usualmente utilizadas nas análises de pobreza, nesta pesquisa, a inclusão foi decorrente de legitimação por meio da consulta popular (primeiro estágio da pesquisa). Ao contrário da grande maioria dos índices disponíveis, a definição do peso de cada dimensão é empírica e não arbitrária. Pelo ordenamento das dimensões, tal peso foi definido pelas pessoas entrevistadas e solicitado a elas que elencassem as quatro privações mais importantes da comunidade onde vivem. Assim, o IC foi elaborado para retratar maiores ou menores carências, em um intervalo entre 0 e 1, segundo a visão da própria população pobre. Quanto mais próximo de 1 estiver o índice, maior a carência multidimensional e, quanto mais próximo de zero, menor a carência.

O IC é um indicador inédito por sua forma de concepção e também pelo fato de apresentar uma alternativa ao processo de ponderação das dimensões que o compõem. Para cada uma das dimensões, foram formuladas 06 (seis) questões que buscavam medir as capacitações das pessoas entrevistadas e construir subíndices por dimensão. Na construção dos subíndices de cada dimensão, as questões utilizadas receberam pesos iguais. Já, no processo de agregação das dimensões para construção do IC agregado, foram utilizados os pesos empíricos. Com base em tais ponderações, o índice apresenta a seguinte estrutura:

$\mathrm{IC}=30 / 100 \mathrm{H}+26 / 100 \mathrm{~S}+22 / 100 \mathrm{TeR}+22 / 100 \mathrm{E}$

em que:

$\mathrm{H}=$ dimensão habitação contribuiu com peso de $30 \%$ do índice;

$\mathrm{S}=$ dimensão saúde contribuiu com $26 \%$ do peso no índice;

$\mathrm{TeR}=$ dimensão trabalho e renda com peso de $22 \%$;

$\mathrm{E}=$ dimensão educação também com $22 \%$.

Na Figura 1, tem-se uma visão geral da distribuição da pobreza, mostrando as regiões da cidade onde se destacam as privações mais intensas. Em geral, evidenciase correlação positiva entre intensidade e extensão ${ }^{1}$.

(1) A Região da Restinga, por exemplo, é mais intensamente pobre do que todas as demais regiões nas dimensões Trabalho e Renda e Saúde e a segunda mais pobre de Porto Alegre na dimensão Habitação estando relativamente melhor na dimensão Educação. 
As regiões com maiores privações são a Restinga, o Eixo Baltazar e a região Nordeste. Nelas, o IC está acima de 0,46. Na sequência, com IC entre 0,429 e 0,459, estão as Regiões Humaitá/Navegantes/Ilhas, Cruzeiro, Cristal, Centro-Sul e Centro. Sob a ótica da pobreza multidimensional, nessas 08 regiões, existe maior intensidade das privações e, para a orientação das políticas públicas, trata-se de um possível indicativo de prioridades.

Figura 1

Índice de carências para as 16 Regiões do Orçamento Participativo de Porto Alegre

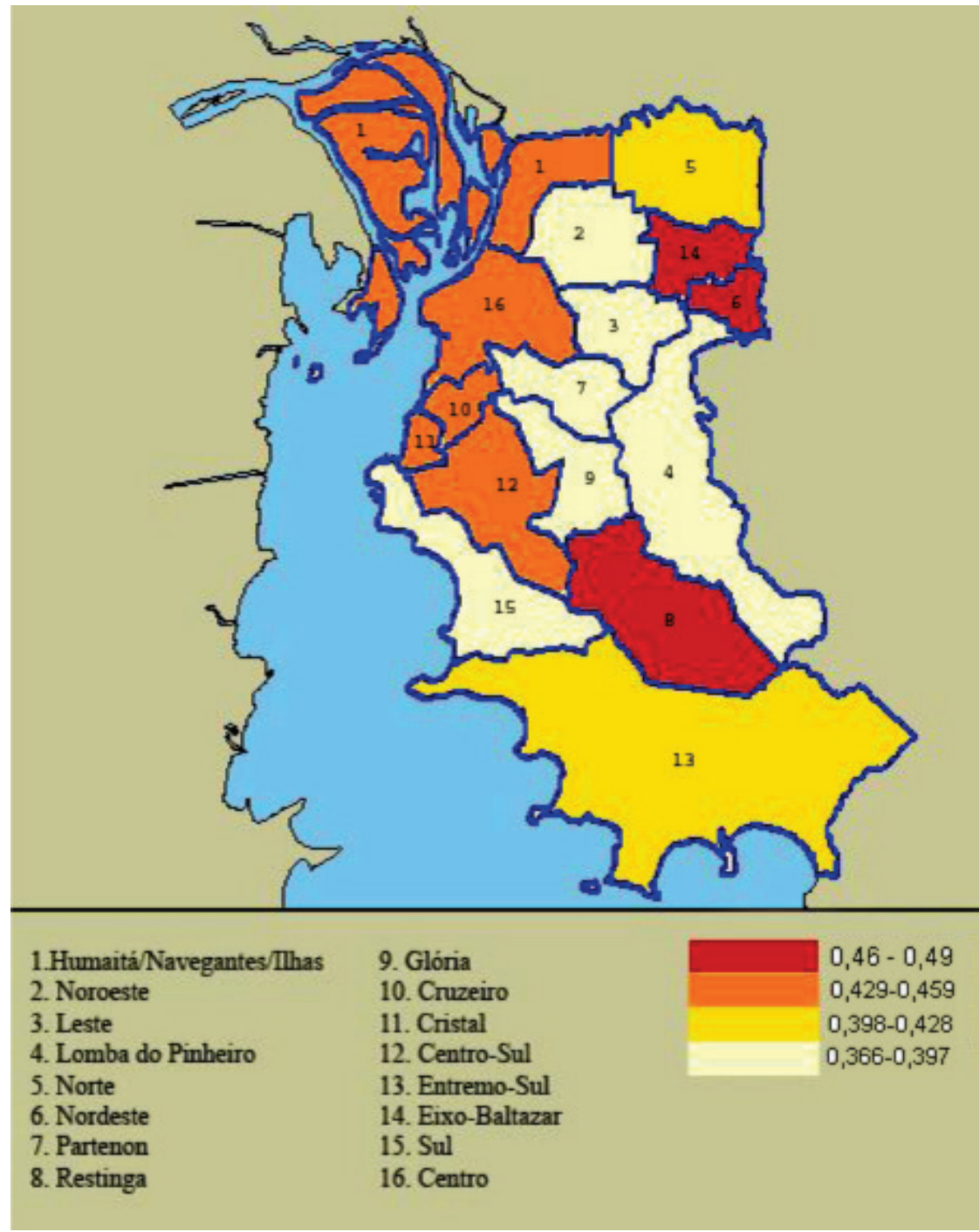


Desagregando os resultados da pesquisa, pode-se ter melhor visão das disparidades regionais e sexuais. Da amostra da pesquisa na segunda etapa, composta por 9003 pessoas, 34,7\% são homens e 64,1\% são mulheres (para os 1,2\% restantes, não se dispunha de informação sobre gênero). Essa desagregação dos dados para homens e mulheres mostra múltiplos aspectos nos quais as particularidades de gênero evidenciam-se. Pela Figura 2, abaixo, observa-se que, em média, os homens pobres pertencem a uma faixa etária mais elevada do que as mulheres em praticamente todas as regiões. Para o conjunto das regiões, a média etária dos homens entrevistados é de 40,1 anos e das mulheres é de 37,7 anos.

Figura 2

Homens e mulheres por faixa etária nas 16 Regiões do Orçamento Participativo

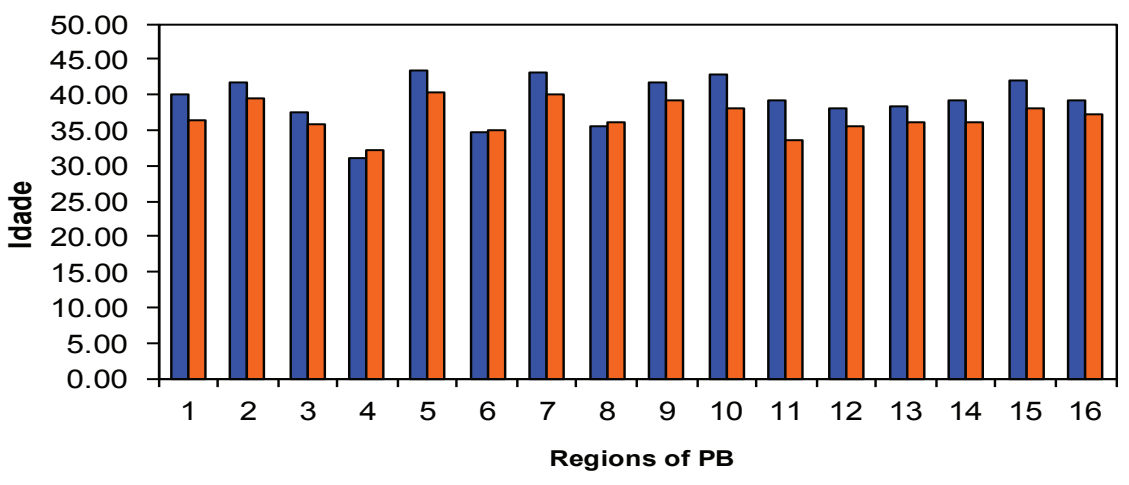

aldade Homens aldade Mulheres

No aspecto acesso à educação formal, a Figura 3 mostra que não existem disparidades significativas no que tange ao número médio de anos de estudo dos homens e mulheres entrevistados. Diferente do que se verifica na média nacional brasileira, em que a mulher tem mais anos de estudo que os homens, de acordo com Olinto e Oliveira (2004), em Porto Alegre, os resultados indicam que os homens estudaram, em média, 6,12 anos e as mulheres 6,17 anos. É possível afirmar que, em média, tanto homens quanto mulheres não estudaram por tempo suficiente para viabilizar a conclusão do Ensino Fundamental. Tal fato poderia indicar que homens e mulheres estão em situação de igualdade em termos de qualificação profissional. $A$ priori, isso deveria proporcionar oportunidades iguais no que tange à realização de funcionamentos de valor em relação ao trabalho. 
Figura 3

Anos médios de estudo de homens e mulheres nas Regiões do Orçamento Participativo de Porto Alegre

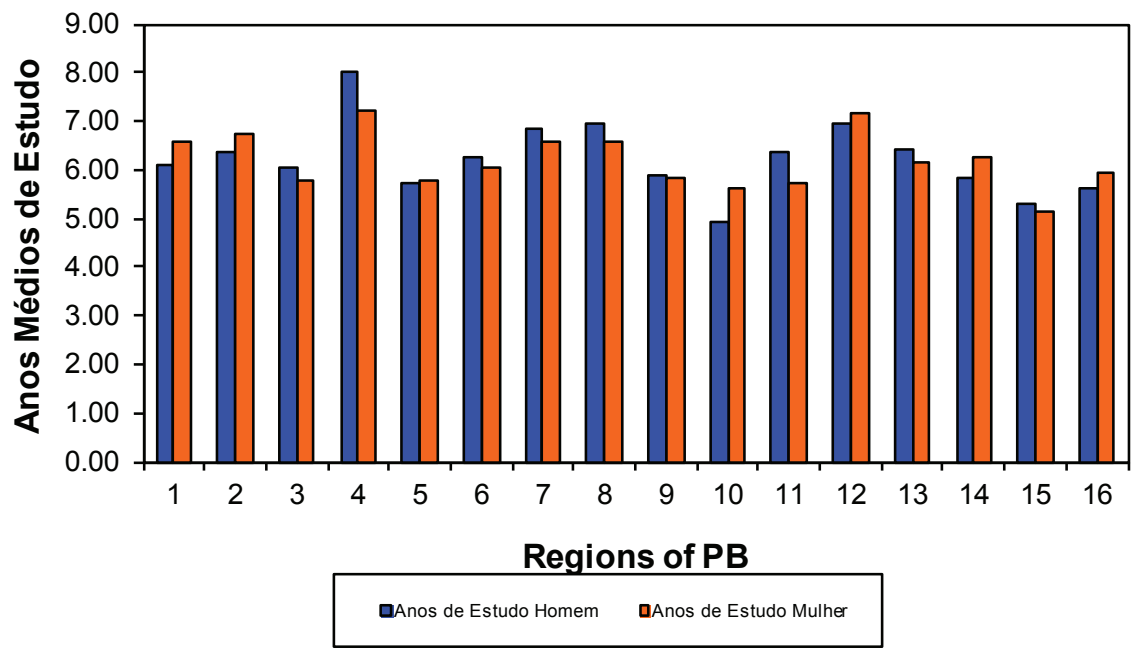

Apesar de os anos médios de estudo serem semelhantes nos dois grupos, quando se observa outros aspectos como, por exemplo, a dimensão renda (Figura 4), aparecem as diferenciações em termos de realizações. Em média, os homens estão em faixas de renda superiores às mulheres. A frequência observada indica que $36,5 \%$ dos homens respondentes situam-se nos estratos de renda inferiores a 1 salário mínimo e 40,3\% das mulheres estão nessa condição. Percebe-se pela figura que, em praticamente todas as regiões, os homens encontram-se em faixa de renda superior àquela recebida pelas mulheres. A única exceção é a Região 10 (Cruzeiro) onde as mulheres aparecem com média de renda superior aos homens. Tal disparidade de rendimento remete à análise das variáveis "privação" que buscaram entender o grau de privação na dimensão emprego e acesso ao mercado formal de trabalho, apresentadas abaixo.

Antes de serem discutidas as privações relacionadas ao emprego e ao mercado formal de trabalho, cabe um olhar sobre a síntese do Índice de Carência nas quatro dimensões (Habitação, Trabalho e Renda, Saúde e Educação) mostrado na Figura 5 que resume o desempenho de homens e mulheres. Confirma-se, pela figura abaixo, que a dimensão Educação é, de fato, a única em que ambos os sexos apresentam desempenho parecido: o Índice de Carência em Educação para os homens é 0,499 $\mathrm{e}$, para as mulheres, 0,508 . Nos outros três indicadores, o desempenho das mulheres é pior que o dos homens, ou seja, o seu IC é mais elevado. No Índice de Carência Trabalho e Renda verifica-se a maior disparidade entre os sexos: IC de 0,307 para os homens e de 0,360 para mulheres. Atentando-se para o fato de que trabalho e renda podem representar um fator determinante de autonomia e independência para o indivíduo, é possível inferir que a disparidade ilustra ainda mais a condição precária 
das mulheres entrevistadas no mercado de trabalho (formal e informal) em Porto Alegre, nos termos apresentados e debatidos também por Olinto e Oliveira (2004).

Figura 4

Faixa de renda de homens e mulheres das 16 Regiões do Orçamento Participativo de Porto Alegre

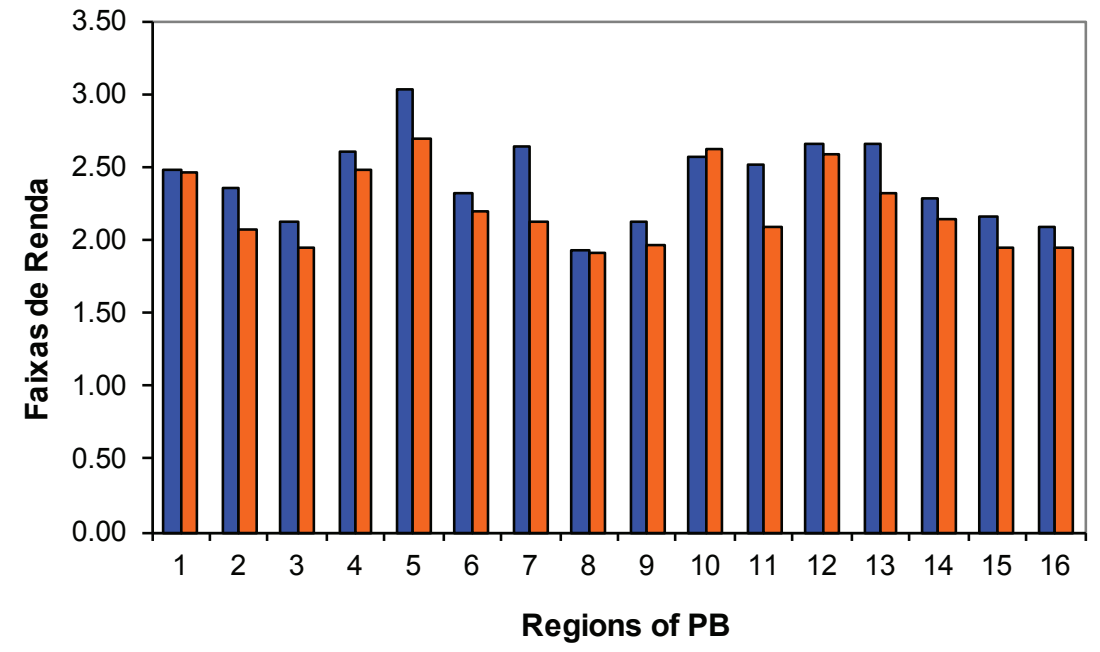

aRenda Homem aRenda Mulher

Figura 5

Desempenho de homens e mulheres nas quatro dimensões da pobreza
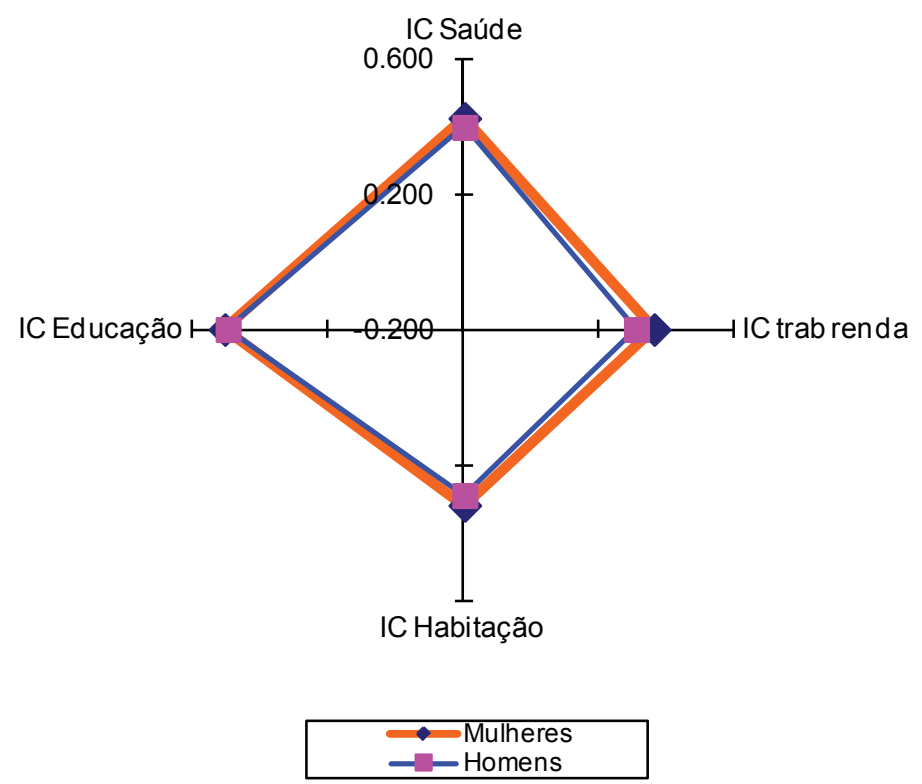
Neste quesito da privação no emprego, mostrado na Figura 6, os números reforçam ainda mais a percepção da desigualdade. Mesmo em um quadro em que as privações já são bastante elevadas (para os pobres de ambos os sexos em Porto Alegre), as mulheres sofrem maiores privações. Observa-se que, na maior parte das regiões, o Índice de Carência feminino na dimensão Emprego supera 0,60 enquanto que para os homens, somente na região 12 (Centro-Sul), ele ultrapassa esse patamar. As diferenças entre os Índices de Carência são visualmente claras em quase todas as regiões, mas os destaques negativos permanecem nas regiões 5 (Norte), 11 (Cristal) e 13 (Extremo Sul) da cidade de Porto Alegre em que as diferenças entre as carências de homens e mulheres são maiores.

Figura 6

Privação na dimensão emprego de homens e mulheres nas Regiões de Porto Alegre

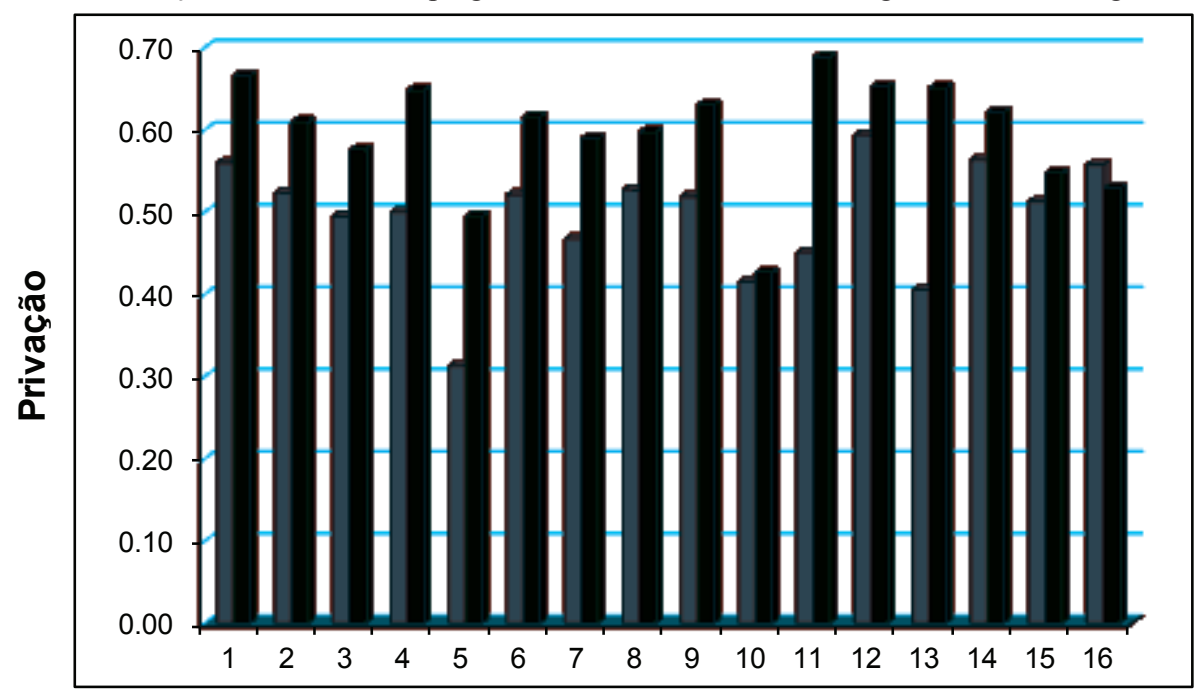

Regiões do OP

Emprego Homem

Emprego Mulher

Igualmente ilustrativas dessas desigualdades são as privações no acesso ao mercado formal de trabalho, mostrados na Figura 7. É possível identificar que, com duas únicas exceções (Regiões 02 - Noroeste - e Região 06 - Nordeste), em Porto Alegre, as mulheres enfrentam maiores privações no acesso à empregabilidade formal, corroborando a versão da relação estreita entre "mulher e trabalhos precários" e entre "mulher e trabalho informal" salientada por Olinto e Oliveira (2004). Pode-se dizer que tal situação tem raízes no histórico estereótipo que dividia sexualmente o trabalho em "trabalho de homem" e "trabalho de mulher", cabendo às últimas uma menor "visibilidade" via trabalho doméstico (ligado à casa e ao espaço privado) 
e ao homem, uma maior "visibilidade" nas ruas, consequentemente, a ocupação preferencial dos postos de trabalho formais (Strey; Cabeda e Prehn, 2004; Gonçalves, 2006).

Figura 7

Privação no acesso ao mercado formal de trabalho das mulheres e homens nas Regiões de Porto Alegre

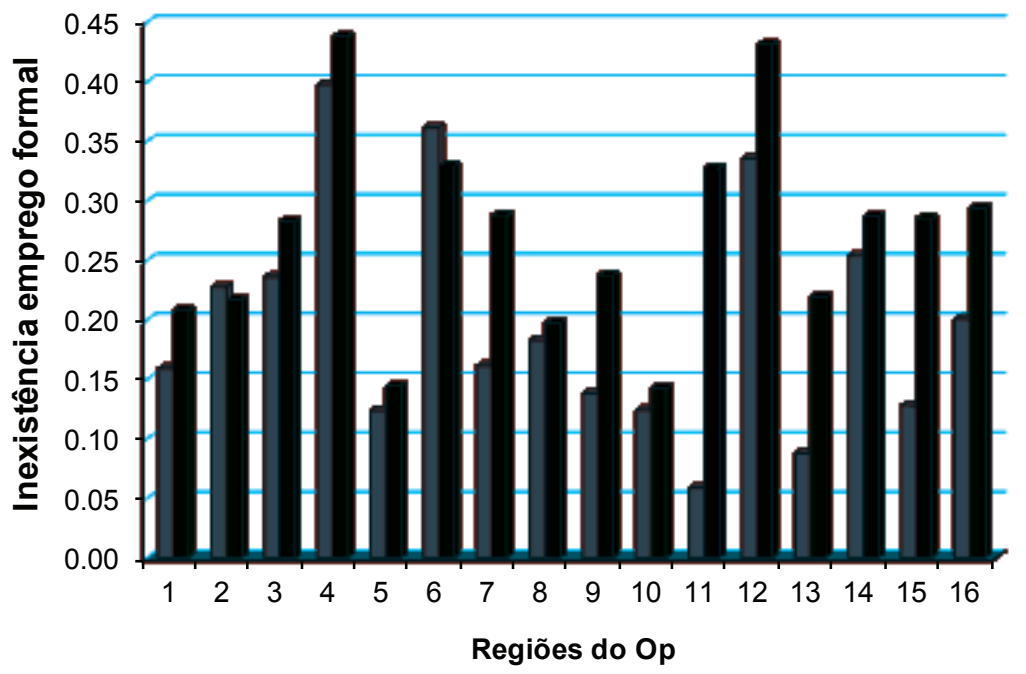

Carteira Assinada Homens $\square$ Carteira Assinada Mulheres

Conforme ressalta Observatório da Cidadania (2005, p. 27), “a divisão de trabalho em função do sexo que atribui às mulheres o trabalho doméstico limita suas oportunidades de acesso a recursos materiais e sociais e à participação nas decisões políticas, econômicas e sociais." Em decorrência disso, elas possuem bens materiais limitados e bens sociais mais restritos (acesso à renda), "o que as coloca numa situação de maior risco de pobreza".

É interessante perceber também que as regiões 4 (Lomba do Pinheiro) e 12 (Centro-Sul) destacam-se negativamente, ou seja, apresentam maior intensidade da privação na questão de acesso ao mercado formal. Isso pode estar vinculado à localização espacial e à existência de muitas ocupações irregulares nas citadas regiões. Em tais casos, além de outras privações decorrentes da condição de pobreza, soma-se a impossibilidade de comprovar endereço residencial na hora de conseguir o emprego formal.

Os dados apresentados na Figura 8 apontam na mesma direção, isto é, reforçam a maior situação de risco de pobreza extrema das mulheres. Por ela, observase que, à exceção das Regiões 1, 7, 11 e 12 (respectivamente Humaitá/Navegantes/ 
Ilhas, Partenon, Cristal e Centro-Sul), as mulheres identificaram-se também como as mais expostas a situações de humilhação decorrentes de sua condição de pobreza.

Figura 8

Exposição de homens e mulheres porto-alegrenses a situações de humilhação

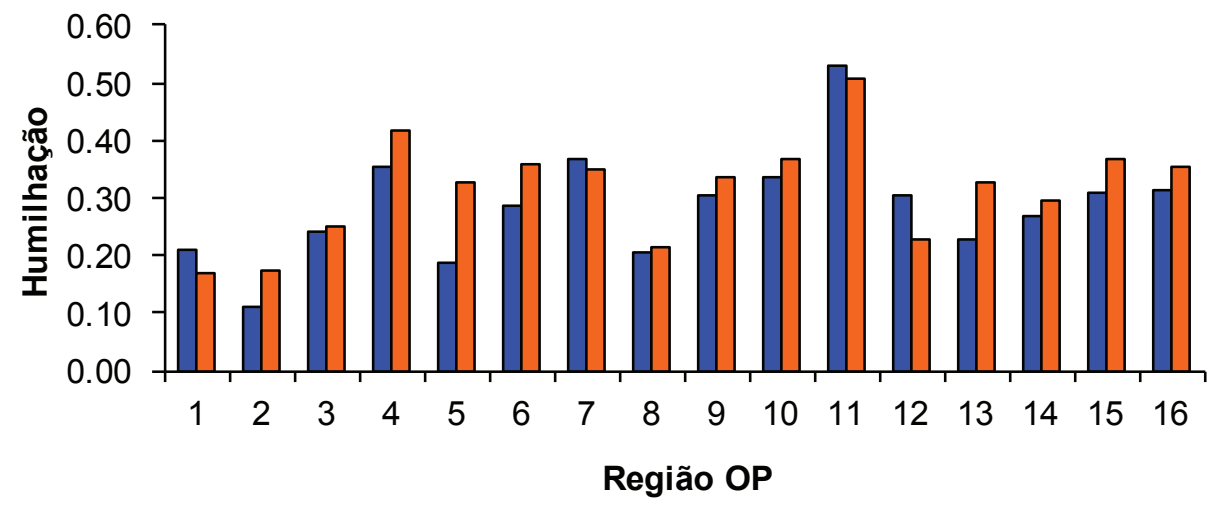

口Homens Humilhação aMulheres Humilhação

Essas variáveis críticas do ponto de vista da percepção pessoal sobre a pobreza podem ser postas em perspectiva por meio dos dados apresentados a seguir. Trata-se das perspectivas de futuro das pessoas.

Figura 9

Existência de Plano para sair da pobreza de homens e mulheres em Porto Alegre

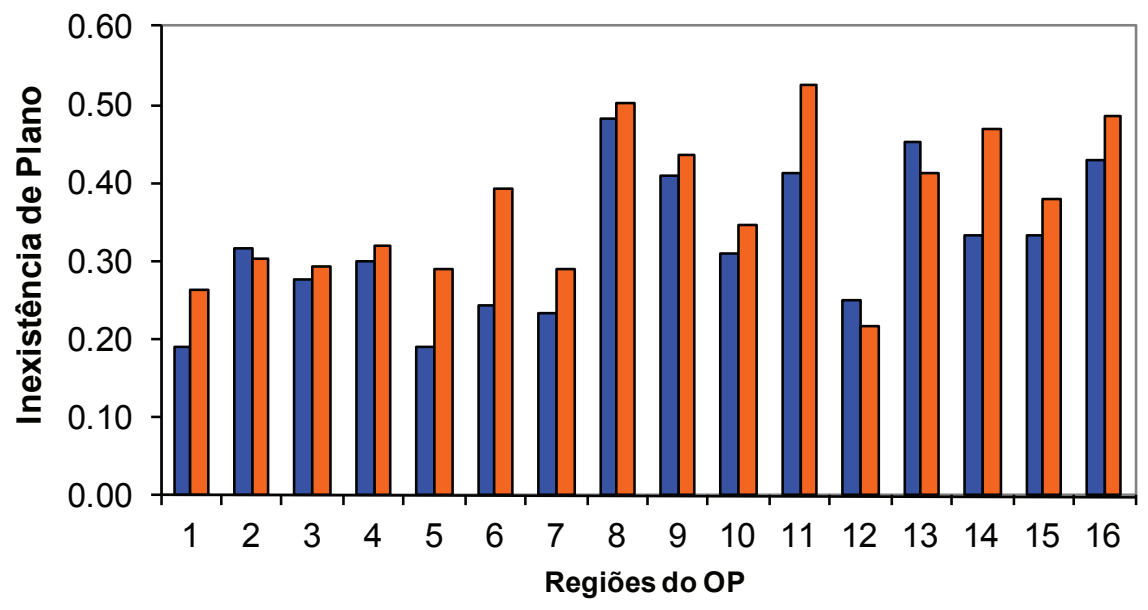

aHomens Tem Plano aMulheres Tem Plano 
Na Figura 9, a evidência é a questão do empoderamento do indivíduo, sua capacidade de ser agente do próprio destino e ter um papel ativo na realização de projetos futuros. Novamente, identifica-se que os indicadores femininos são piores que os dos homens. Perguntados sobre ter ou não plano (s) para saírem da condição de pobreza, os homens responderam mais positivamente do que as mulheres, com exceção de três regiões da cidade (regiões 1, 12 e13). Às mulheres, parece evidenciarse maior "resignação" diante dessa condição.

Ainda no campo das perspectivas, um último destaque cabe ao número médio de pessoas em quem os entrevistados dizem confiar. Em tal caso, entende-se que se trata do número de pessoas com quem podem contar em situações críticas. Os homens apontaram que, em média, confiam em 2,4 pessoas; as mulheres, em 2,29 pessoas.

Sintetizando o tema da situação de risco de pobreza extrema das mulheres, constata-se que elas se consideram relativamente mais submetidas às humilhações, apresentam piores perspectivas dada a menor incidência de entrevistadas que planejam sair da pobreza e ainda contam com menor número de pessoas em quem confiar.

Os resultados da pesquisa permitem afirmar que a pobreza feminina expressase diferente e deve ser entendida de maneira distinta da pobreza masculina. No mínimo, cabe observar que os dados referentes à pobreza com enfoque agregado (por exemplo, no âmbito municipal ou regional) ou com enfoque familiar precisam ser vistos com restrição. Compreender a pobreza multidimensional talvez implique em compreender também que "as pessoas mantêm relações assimétricas" (Observatório da Cidadania, 2005, p. 27).

Pode-se dizer, ainda concordando com o Observatório, que os dados apresentados atuam não apenas no sentido da medição da pobreza, mas “ajuda(m) a torná-la visível e cumpre(m) um papel importante no desenvolvimento e na implementação das políticas públicas" (p. 28). Ademais, a perspectiva de gênero utilizada amplia o conceito de pobreza e reforça a necessidade de compreendermos suas múltiplas dimensões.

\section{Conclusões}

As reflexões e os dados aqui apresentados propunham-se a um duplo desafio. Primeiro, reconhecer e dar visibilidade às múltiplas dimensões da pobreza, incluindo aí seus aspectos espaciais e as particularidades das desigualdades sexuais em Porto Alegre. Segundo, contribuir no sentido de revelar a realidade das desigualdades e produzir informação visando a legitimar questões de fundo sobre o tema, sensibilizar a sociedade e, sobretudo, auxiliar e influenciar as políticas públicas. 
Enfatizou-se que a mudança de abordagem no estudo da pobreza e o tratamento de suas múltiplas dimensões representam um avanço em relação às clássicas distinções entre pobres e ricos baseadas apenas nos critérios de renda. Ao enfatizar o peso de outras dimensões, como Habitação, Saúde e Educação, na manifestação daquilo que consideram relevantes para uma vida "digna de ser vivida", as pessoas entrevistadas estavam apenas explicitando o que realmente importa para elas e suas dificuldades de realização dos funcionamentos de valor. Mesmo que se trate de dimensões tradicionalmente "críticas" no tema da pobreza, o que se verificou é que, entre os pobres de Porto Alegre, consistem dimensões e temas não resolvidos os quais afetam proporcionalmente mais as mulheres.

Se os resultados podem ser inspiradores para políticas públicas ao indicar em quais regiões da cidade estão as maiores carências, também o devem no que tange às dimensões mais importantes às pessoas e ao tratamento diferenciado a ser dado para as desigualdades entre homens e mulheres. Na verdade, é uma questão de como se apropriar de resultados de pesquisa dessa natureza.

Em Porto Alegre, por exemplo, políticas públicas gerais de combate à pobreza que busquem lidar com situações de maior privação poderiam centrar esforços em regiões como a Restinga, o Eixo Baltazar e a região Nordeste da cidade. Mesmo assim, esse ainda seria um critério de priorização geral, visto que não comporta nem o olhar sobre os subíndices das dimensões, nem sobre as questões de gênero.

Caso as políticas fossem orientadas pelas dimensões prioritárias, os "pesos" definidos por meio do processo de consulta mostraram a seguinte ordem: Habitação, Saúde, Trabalho e Renda e Educação. No mínimo, tal sequência poderia ser indicativa de prioridades para as políticas.

Igualmente, ao se considerar o recorte de gênero, tais políticas poderiam considerar que as mulheres em questão, aquelas em condição de pobreza e privações em Porto Alegre, apresentam maiores disparidades em relação aos homens no quesito Trabalho e Renda e maiores privações no quesito privação no emprego. Assim, tal aspecto poderia constituir-se em um indicativo de gênero para políticas de trabalho e renda no município. Na mesma linha, se tais políticas visassem a reduzir a distância entre as privações de homens e mulheres no quesito emprego, a priorização poderia acontecer regionalmente onde elas são maiores, como os casos das regiões Norte, Cristal e Extremo Sul da cidade.

Ainda a título de ilustração dessa dimensão Trabalho e Renda, caso a política pública tivesse como foco a privação no acesso ao mercado formal e visasse a priorizar regiões da cidade com maiores privações, a mesma poderia centrar esforços nas regiões Lomba do Pinheiro, Nordeste e Centro-Sul, onde as privações apontadas são maiores. Utilizando, contudo, como critério adicional as diferenças de gênero, a 
mesma política poderia priorizar as regiões Lomba do Pinheiro e Centro Sul, visto que nessas duas regiões a condição das mulheres é relativamente pior que a dos homens, se comparada com as demais regiões da cidade.

Em resumo, trata-se de compreender que, além da segregação social decorrente da pobreza, existe ainda uma segregação "dentro" da pobreza. As mulheres sofrem privações mais intensas em suas capacitações para realizar funcionamentos de valor. Sofrem quando buscam possuir moradia digna, procuram estar livres de doenças evitáveis, desejam ser adequadamente educadas e ter condições de gerar seu próprio sustento com um trabalho digno e com proteção social. Dentre os pobres, as mulheres são as que apresentam maiores restrições em seu conjunto capacitário, o que deve ser digno de atenção para a construção de políticas públicas.

\section{Referências bibliográficas}

ARAÚJO, Clara; SCALON, Celi (Org.). Gênero, família e trabalho no Brasil. Rio de Janeiro: Editora da FGV, 2005.

CARREIRA, Denise (Coord.). Igualdade de gênero no mundo do trabalho: projetos brasileiros que fazem a diferença. São Paulo: Cortez; Brasília: Fundo de Gênero BrasilCanadá (FIG), 2004.

CHIAPPERO MARTINETTI, E. A Multidimensional assessment of well-being based on Sen's functioning approach. Rivista Internazionale di Scienze Sociallu, v. 108, p. 207-239, 2000.

COMIM, F. BAGOLIN, I. Aspectos qualitativos da pobreza no Rio Grande do Sul. Ensaios FEE, Porto Alegre, v. 23, Número Especial, 2002.

. Operatiozalizing Sen's capability approach. Paper presented at Conference Justice and Poverty: examining Sen's Capability Approach, Cambridge, 5-7 Jun. 2001.

DEATON, Angus. The analysis of household surveys: a microeconomic approach to development policy. World Bank Publications, 1997.

FOSTER, James; SEN, Amartya. On economic inequality after a quarter century. In: SEN, Amartya. On economic inequality: with a substantial annex after a quarter century by J. Foster \& A. Sen. Oxford University Press, 1997.

GONÇALVES, Andréa Lisly. História e gênero. Belo Horizonte: Autêntica, 2006.

NARAYAN, D. Voices of the poor - Can anyone hear us? Washington, D.C.: The World Bank, Oxford University Press, 2000.

NUSSBAUM, M. Sex and social justice. Cambridge: CUP, 1999. Woman and human development. Cambridge: CUP, 2000.

OBSERVATÓRIO DA CIDADANIA. Observatório da cidadania 2005: rugidos e sussurros. Montevidéu: ITe M - Instituto del Tercer Mundo; Rio de Janeiro: IBASE, 2005.

OLINTO, Gilda; OLIVEIRA, Zuleica Lopes Cavalcanti. Gênero e trabalho precário no Brasil urbano: perspectivas de mudança. In: Encontro Nacional de Estudos Populacionais 
(ABEP), 14, Caxambu (MG), set. 2004. Anais...

PRESSMAN, S.; SUMMERFIELD, G. The economic contributions of Amartya Sen. Review of Political Economy. v. 12. n. 1, 2000.

QIZILBASH, M. A note on the measurement of poverty and vulnerability in the South Africa context. Journal of International Development, v. 14, p. 757-772, 2002.

ROBEYNS, Ingrid. The capability approach: a theoretical survey. Journal of Human Development, v. 6, n. 1, 2005.

. The capability approach: an interdisciplinary introduction, teaching material for the training course preceding the 3rd International Conference on the capability approach, Pavia, Sept. 2003.

SCOTT, Parry; CORDEIRO, Rosineide. (Org.). Agricultura familiar e gênero: práticas, movimentos e políticas públicas. Recife: Ed. Universitária UFPE, 2006.

SEN, A. K. Capability and well-being. In: SEN, A.; NUSSBAUN, M. (Ed.). The quality of life. Oxford: Clarendon Press, 1993.

. Commodities and capabilities. Amsterdam: North Holland, 1985.

- Desenvolvimento como liberdade. São Paulo: Companhia das Letras, 2000.

. Development as Freedom. Oxford, New York, 1999.

. Development: which way now? The Economic Journal, v. 93, p. 745-762, 1983 b.

. Equality of what? In: McMURRIN, S. (Ed.). Tanner lectures on human values.

Cambridge: Cambridge University Press, 1980.

. Inequality re-examined. Oxford: Clarendon Press, 1992.

. Poverty and famines: an essay on entitlement and deprivation. Oxford: Oxford

University Press, 1982.

Resources, values and development. Oxford: Basil Blackwell, 1984b.

. The living standard. Oxford Economic Paper, 36, 1984.

. The standard of living. Cambridge: Cambridge University Press, 1987.

SOCIAL WATCH . Social Watch Report 2007: in dignity and rigths. Montevideo: Instituto del Tercer Mundo, 2007.

SMITH, A. Wealth of nations. Campbell and Skninner Edition, v. I, book 2, 1976.

STREY, Marlene N.; CABEDA, Sonia T. Lisboa; PREHN, Denise R. (Org.). Gênero e cultura: questões contemporâneas. Porto Alegre: EDIPUCRS, 2004. 


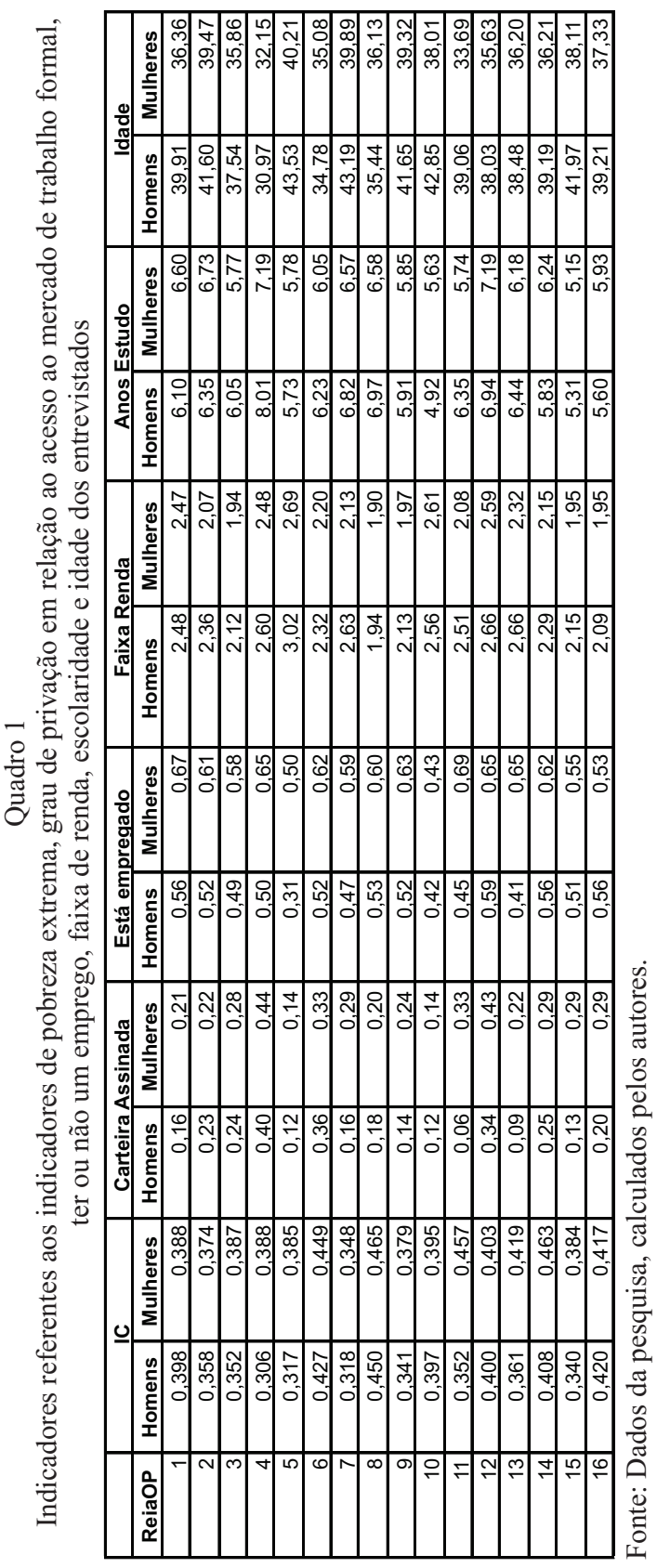

